\title{
Simulation of Hydrogen Distribution and Effect of Engineering Safety Features (ESFs) on its Mitigation in a WWER-1000 Containment
}

\author{
Omid Noorikalkhoran ${ }^{1, *}$, Najmeh Jafari ${ }^{2}$, Massimiliano Gei ${ }^{1}$, Rohollah Ahanagari ${ }^{3}$ \\ ${ }^{1}$ School of Engineering, Cardiff University, Wales, UK \\ ${ }^{2}$ National Research Tomsk Polytechnic University, Tomsk, Russia \\ ${ }^{3}$ Nuclear Science and Technology Research Institute (NSTRI), Tehran, Iran
}

Number of manuscript pages: 36

Number of Figures: 18

Number of Tables: 9

* Corresponding author's Email address: NoorikalkhoranO@cardiff.ac.uk 


\begin{abstract}
:
In this study, thermal-hydraulic parameters inside the containment of WWER1000/v446 nuclear power plant are simulated in a Double Ended Cold Leg (DECL) accident for short and long times (by using CONTAIN 2.0 and MELCOR 1.8.6 codes) and the effect of the spray system as an Engineering Safety Feature (ESF) on parameters mitigation are analyzed with the former code. Along with the development of the accident from Design Basis Accident (DBA) to Beyond Design Basis Accident (BDBA), the zircaloy-steam reaction becomes the source of in-vessel hydrogen generation. Hydrogen distribution inside the containment is simulated for long time (using CONTAIN and MELCOR) and the effect of recombiners on its mitigation are analyzed (using MELCOR). Thermal-hydraulic parameters and hydrogen distribution profiles are presented as the outcome of the investigation. By activating the spray system, the peak points of pressure and temperature occur in the short time and remain below the maximum design values along the accident time. It is also shown that recombiners have a reliable effect on reducing the hydrogen concentration below flame-propagation limit in the accident localization area. The parameters predicted by CONTAIN and MELCOR are in good agreement with the Final Safety Analysis Report. The noted discrepancies are discussed and explained.
\end{abstract}

Keywords: Containment; Hydrogen Distribution; In-vessel Severe Accident; Recombiners; CONTAIN; MELCOR 


\section{Introduction}

The analysis of the nuclear power plant is performed to justify and substantiate the nuclear safety of the plant in case of design disturbances due to malfunction or failure of equipment [1]. To protect people and the environment from the consequences of an accident, several sequential physical constraints for the confinement of radioactive materials are put in place. Their specific design may vary depending on the activity of the material and on the possible deflections from a normal operation that could lead up to loss of some barriers. Those confining the fission products are typically fuel matrix, fuel cladding, the boundary of the reactor coolant system and, finally, the containment system.

A specific type of Large Break Loss Of Coolant Accident (LB-LOCA) is DECL (Double Ended Cold Leg) that corresponds to a total guillotine type of break in cold leg pipe and is one of the most hazardous design basis accident in the reactor containment [2]. The progression of this accident without the interference of engineering safety features can lead to the release of water and steam mass and energy into the containment (Design Basis Accident - DBA), in-vessel hydrogen generation (Beyond Design Basis Accident - BDBA), core melting and ex-vessel hydrogen generation (Severe Accident - SA) and finally hydrogen explosion and loss of containment integrity.

Hydrogen can be generated by different sources inside the containment. In the early phase, it can be generated as a result of hot fuel clad (zircaloy) reaction with steam while in the latephase generation, it will be the product of molten core material mixture (Corium) reaction with the concrete structure of containment [3].

In the case of hydrogen generation (in-vessel or ex-vessel), prediction of hydrogen distribution (concentration map of hydrogen) in different locations (rooms) of reactor containment can help the designer to modify the safety features and find the best location for their installation to 
avoid the hydrogen combustion or explosion. The concentration distribution of hydrogen also needs to be assessed to ensure that, due to the hydrogen concentration distribution in the containment, sustained deflagration or detonation, for which the containment is not designed, should not occur. According to the Code of Federal Regulations, title 10 (CFR 10), by Nuclear Regulatory Commission (NRC) of the United States, each Safety Analysis Report (SAR) should provide a system for hydrogen control that can safely accommodate hydrogen generated by the equivalent of a $100 \%$ fuel-clad metal water reaction [4].

Given the importance of these, several studies were conducted in recent years to evaluate the thermal-hydraulic behavior of the containment in an accident like LB-LOCA and hydrogen distribution as its consequences; a better understanding of thermal-hydraulic parameters of LBLOCA can provide the initial conditions for hydrogen distribution simulation.

In some of these studies, containment parameters due to LB-LOCA were simulated by using different tools and models. Noori-kalkhoran et al. have applied different tools for the simulation of thermal-hydraulic parameters of containment due to DECL: CONTAIN code, Single-cell, and Multi-cell models [5,6]. The GOTHIC code has been used widely to simulate the parameters in IRIS [7], ABWR [8], BWR Mark III [9] and PWR [10] containments. This code is a general purpose thermal-hydraulic tool that can be used to model multi-component and multi-phase flow systems in multi-dimensional geometries. This code is suitable for safety analysis of nuclear power plant containment buildings [11]. Recently, an interesting study by Povilaitis et al. [12] about the uncertainty and sensitivity analysis for a generic containment severe accident has demonstrated that both user effects and input uncertainties play a similar role. In the review by De Boeck [13], the author has described the main threats to the containment integrity and the state of knowledge and remaining uncertainties. From another point of view, some studies have dealt with the effects of ESFs on mitigation of LOCA consequence inside the containment. Numerical investigations of the response of the passive 
containment cooling system and containment under a DELB (Double Ended Leg Break) LOCA were performed by $\mathrm{Yu}$ et al. [14]. Effects of spray on the performance of the hydrogen mitigation system during LB-LOCA was studied by Huang et al. in CPR1000 NPP [15]. Guk et al. reported on the thermal-hydraulic evaluation of passive containment cooling system of improved APR+ during LOCAs [16].

Hydrogen generation and distribution inside NPP containment due to LOCA have also been studied by different authors for different reactor types such as PWR [17]. In recent years, use of CFD codes has increased for the analysis of the hydrogen behavior within NPP containments. Ravva et al. [18] have developed a sump model for containment hydrogen distribution by using CFD models. Martin-Valdepenas et al. improved a CFD code for the analysis of hydrogen behavior within containment [19]. A CFD analysis of hydrogen volumetric concentration in a Mark II BWR containment system was studied by Miguel Gomez-Torres et al. [20]. Besides CFD methods, some other methods and codes have been employed for simulation of hydrogen distribution in the containment. Cascade fuzzy neural networks were selected by Choi et al. for prediction of hydrogen concentration in NPP containment [21]. Szabo et al. coupled MELCOR and GASFLOW to obtain the hydrogen distribution in the containment [22]. They designed an interface to receive the source term from MELCOR and send back the containment pressure during run time. This coupling was used to postulate LOCA in a generic PWR. Different methods and tools to mitigate the hydrogen concentration inside containment in accident situation were also analyzed. Breitung et al. developed a systematic step-by-step procedure for the deterministic analysis of hydrogen behavior and mitigation in severe accidents [23], while a generic approach for designing and implementing a Passive Autocatalytic Recombiner (PAR) was proposed by Bachellerie et al. [24] under the project "PARSOAR". 
Bushehr Nuclear Power Plant (BNPP)-WWER-1000/v446- is the only representative of this version built around the world. Its special containment design (spherical steel inner layer with outer cylindrical concrete one) yields unique features such as geometry, specification and behavior in different containment accidents. In this study, first, thermal-hydraulic parameters of WWER-1000/v446 containment are simulated in short and long time by using CONTAIN and MELCOR codes and results are compared with BNPP FSAR (ANGAR code) to benchmark the simulation. Next, the effect of spray as an ESF is studied in the mitigation of containment pressure and temperature by using CONTAIN code. It is assumed that accident will develop from DBA to BDBA and in-vessel hydrogen generation will occur (this assumption is based on LB-LOCA with Emergency Core Cooling System (ECCS) active part failure due to NPP black out). Finally, hydrogen distribution is predicted by both codes and the effects of recombiners on hydrogen mitigation is studied by using MELCOR. Thermalhydraulic and hydrogen distribution map of containment is also presented in the last second of the accident (about $10^{5}$ seconds) in the absence of ESFs. Reasons for discrepancies between MELCOR and CONTAIN codes results are presented and explained.

\section{BNPP containment}

Bushehr Nuclear Power Plant (BNPP) is a Russian type pressurized water reactor (WWER). Its electrical capacity is $1000 \mathrm{MW}$ with $3000 \mathrm{Mw}$ thermal capacity. It has a dual-layer cylindrical containment. The inner steel containment that has an average thickness of $30 \mathrm{~mm}$ with $56 \mathrm{~m}$ diameter and contains the main systems, such as core, primary loop components, Steam Generators (SGs) and safety features. The outer containment is a concrete construction with a density of $2.35 \mathrm{~g} / \mathrm{cm}^{3}$. Its upper side has a thickness of about $1750 \mathrm{~mm}$ whereas the lower side is about $2000 \mathrm{~mm}$ thick. There is a $1650 \mathrm{~mm}$ gap between the inner and outer layer [25]. 
The containment was designed based on withstanding against i) simultaneous occurrence of maximum peak pressure in the postulated DECL accident and station black out (that leads to ECCS active part failure) as internal worst-case accident and ii) airplane crash as an external worst-case accident (crash of Boeing-747 on containment building) [25]. Figure 1 shows the containment structure whereas the main specifications and design parameters are listed in Tables 1 and 2, respectively.

Table 1. BNPP containment specifications

\begin{tabular}{ll}
\hline Parameter & value \\
\hline Steel containment inner diameter $(\mathrm{mm})$ & 28,000 \\
Steel thickness $(\mathrm{mm})$ & 30 \\
Gap thickness $(\mathrm{mm})$ & 1650 \\
Concrete thickness $(\mathrm{mm})$ & 1750 \\
Containment free volume $\left(\mathrm{m}^{3)}\right.$ & 71,040 \\
The total area of all the concrete walls $\left(\mathrm{m}^{2}\right)$ & 18,860 \\
\hline
\end{tabular}

Table 2. Design parameters for BNPP

\begin{tabular}{ll}
\hline \multicolumn{1}{c}{ Parameter } & value \\
\hline Maximum internal pressure at $150{ }^{\circ} \mathrm{C}(\mathrm{MPa})$ & 0.46 \\
Maximum pneumatic test pressure at a temperature of up to $60{ }^{\circ} \mathrm{C}(\mathrm{MPa})$ & 0.51 \\
Maximum (averaged over the volume) temperature $\left({ }^{\circ} \mathrm{C}\right)$ & 150 \\
\hline
\end{tabular}




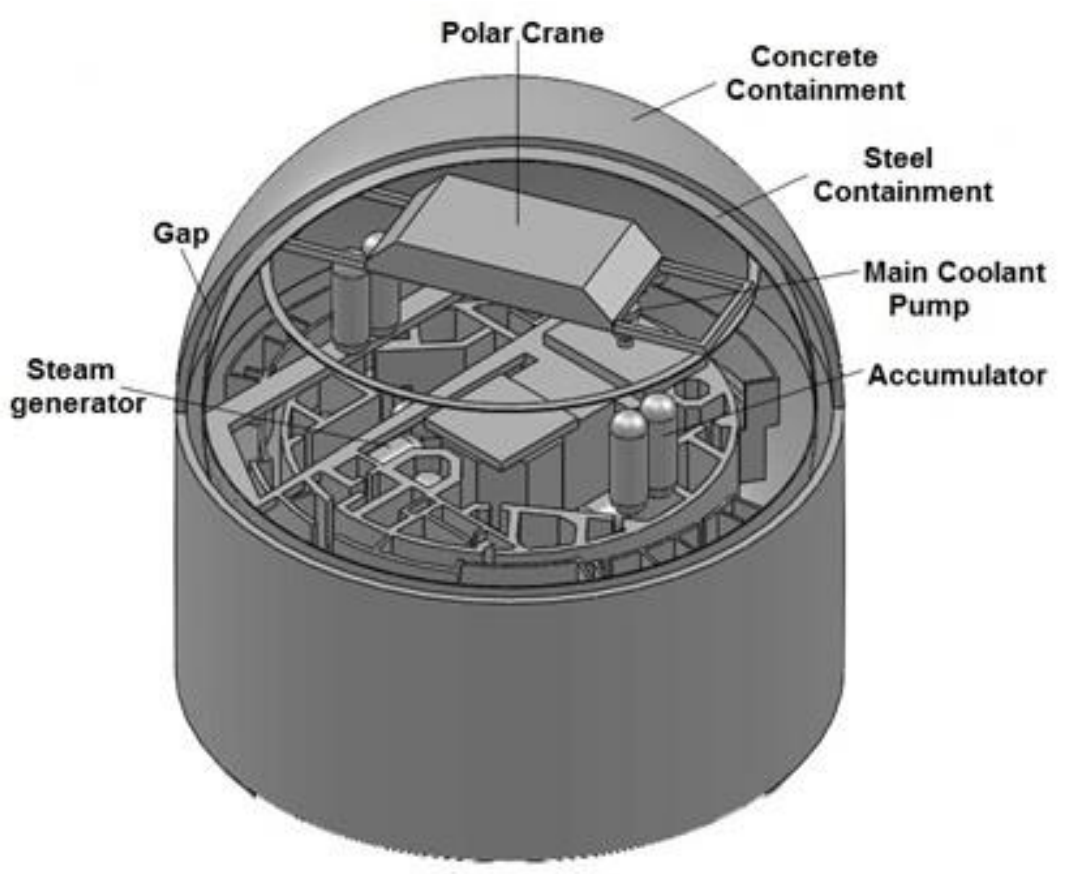

Figure 1. BNPP containment structure

\section{Hydrogen in NPP containment}

Following LOCA, hydrogen gas may accumulate within the containment from various sources. If a sufficient amount of hydrogen is generated, it may react with oxygen present in the containment vessel atmosphere at rates rapid enough to lead to high temperatures and significant over pressurization of containment. The hydrogen concentration monitoring and emergency removal system is designed to control the concentration of hydrogen that may be released within the containment atmosphere following a LOCA.

\subsection{Hydrogen generation}

Hydrogen may get generated because of the following three mechanisms depending on the accident progression $[3,26]$ :

- Oxidation of zircaloy cladding material that is in the early phase of the accident (invessel generation) 
- oxidation of metallic materials (More $\mathrm{Zr}$ and $\mathrm{Cr}$ ) by the reaction of corium with concrete containment in the late phase of the accident (ex-vessel generation)

- oxidation of metallic materials in Direct Containment Heating phenomena (DCH).

\subsubsection{In-vessel hydrogen generation}

The main source of the in-vessel hydrogen generation is as result of Zircaloy and steam reaction (Oxidation of fuel clad) but depends on the type of reactor can also be as result of steel and Boron carbide $\left(\mathrm{B}_{4} \mathrm{C}\right.$ - absorbing material) oxidation. It is generally observed that about $10 \%$ to $15 \%$ of the total in-vessel hydrogen generation is due to steel oxidation [3].

\subsubsection{Ex-vessel hydrogen generation}

In the first hours of Molten Core Concrete Interaction (MCCI), zirconium and chromium masses are oxidized by steam thus producing $\mathrm{H}_{2}$ and $\mathrm{CO}$; after that, $\mathrm{Fe}$ is oxidized for about a day until the penetration is completed [27].

In the initial hours of the accident or even less, almost all the masses of zirconium and chromium will be oxidized as result of the molten core-concert interaction. During the coreconcrete interaction, $\mathrm{CO}$ can be released depending on the composition of the basement concrete. So, the results are highly depended to plants specifications. The so-called 'flammable mixture' $\left(\mathrm{H}_{2}+\mathrm{CO}\right)$ in the containment must take into account in the risk evaluation due to hydrogen burning. Table 3 lists the hydrogen formation by different sources due to LOCA in BNPP. The profiles of hydrogen generation are shown in Figure 2. 
Table 3. Hydrogen formation from different sources due to LOCA in BNPP [25]

\begin{tabular}{|c|c|c|c|c|c|c|c|c|c|c|c|c|c|}
\hline \multirow{3}{*}{$\begin{array}{l}\text { Hydrogen formation } \\
\text { by different sources } \\
\text { and total mass, } \mathrm{kg}\end{array}$} & \multirow{3}{*}{$\begin{array}{c}\text { Condition } \\
*\end{array}$} & \multicolumn{12}{|c|}{ Time hrs/days } \\
\hline & & 1 & 2 & 4 & 8 & 24 & 48 & 72 & 120 & 240 & 360 & 480 & 744 \\
\hline & & - & - & - & - & 1 & 2 & 3 & 5 & 10 & 15 & 20 & 31 \\
\hline $\begin{array}{l}\text { Hydrogen dissolved in the coolant, } \\
\text { m(a) }\end{array}$ & $\mathbf{N}$ & 2.3 & 2.3 & 2.3 & 2.3 & 2.3 & 2.3 & 2.3 & 2.3 & 2,3 & 2.3 & 2.3 & 2.3 \\
\hline Steam-zirconium reaction, $\mathbf{m}_{(\mathrm{b})}$ & $\mathbf{A}$ & 12.5 & 12.5 & 12.5 & 12.5 & 12.5 & 12.5 & 12.5 & 12.5 & 12,5 & 12.5 & 12.5 & 12.5 \\
\hline Radiolysis in the core, $\mathbf{m}_{(\mathrm{c})}$ & $\mathbf{N}$ & 1.5 & 2.2 & 3.8 & 6.1 & 12.5 & 19.5 & 26.8 & 37.7 & 61,4 & 80.5 & 97.3 & 102.2 \\
\hline Radiolysis in fuel pool, $\mathbf{m}_{(\mathrm{d})}$ & $\mathbf{N}$ & 0.1 & 0.2 & 0.4 & 0.6 & 1.8 & 3.2 & 4.9 & 7.8 & 15,2 & 23.0 & 30.1 & 44.5 \\
\hline Radiolysis in the sump, $\mathbf{m}_{(\mathrm{e})}$ & $\mathbf{A}$ & 1.05 & 2.46 & 4.46 & 7.66 & 15.91 & 23.14 & 28.07 & 35.54 & 50,04 & 62.47 & 73.66 & 94.88 \\
\hline Radiolysis of steam, $\mathbf{m}_{(\mathfrak{f})}$ & $\mathbf{A}$ & 0.03 & 0.06 & 0.12 & 0.48 & 0.72 & 0.72 & 0.72 & 0.72 & 0,72 & 0.72 & 0.72 & 0.72 \\
\hline $\begin{array}{l}\text { Decomposition of hydrazine- } \\
\text { hydrate, } \mathbf{m}_{(\mathrm{g})}\end{array}$ & $\mathbf{N}$ & 26.8 & 40.2 & 46.9 & 53.8 & 53.8 & 53.8 & 53.8 & 53.8 & 53,8 & 53.8 & 53.8 & 53.8 \\
\hline $\begin{array}{l}\text { Hydrogen in the containment } \\
\text { atmosphere under } \mathrm{STP}, \mathrm{m}_{(\mathrm{)})}\end{array}$ & $\mathbf{N}$ & 19.3 & 19.3 & 19.3 & 19.3 & 19.3 & 19.3 & 19.3 & 19.3 & 19,3 & 19.3 & 19.3 & 19.3 \\
\hline Total ingress of hydrogen, $M$ & & 63.58 & 79.04 & 89.78 & 102.74 & 118.83 & 134.46 & 148.39 & 169.66 & 215,26 & 254.59 & 289.68 & 330.20 \\
\hline
\end{tabular}

*N=Normal Operation, A=Accident

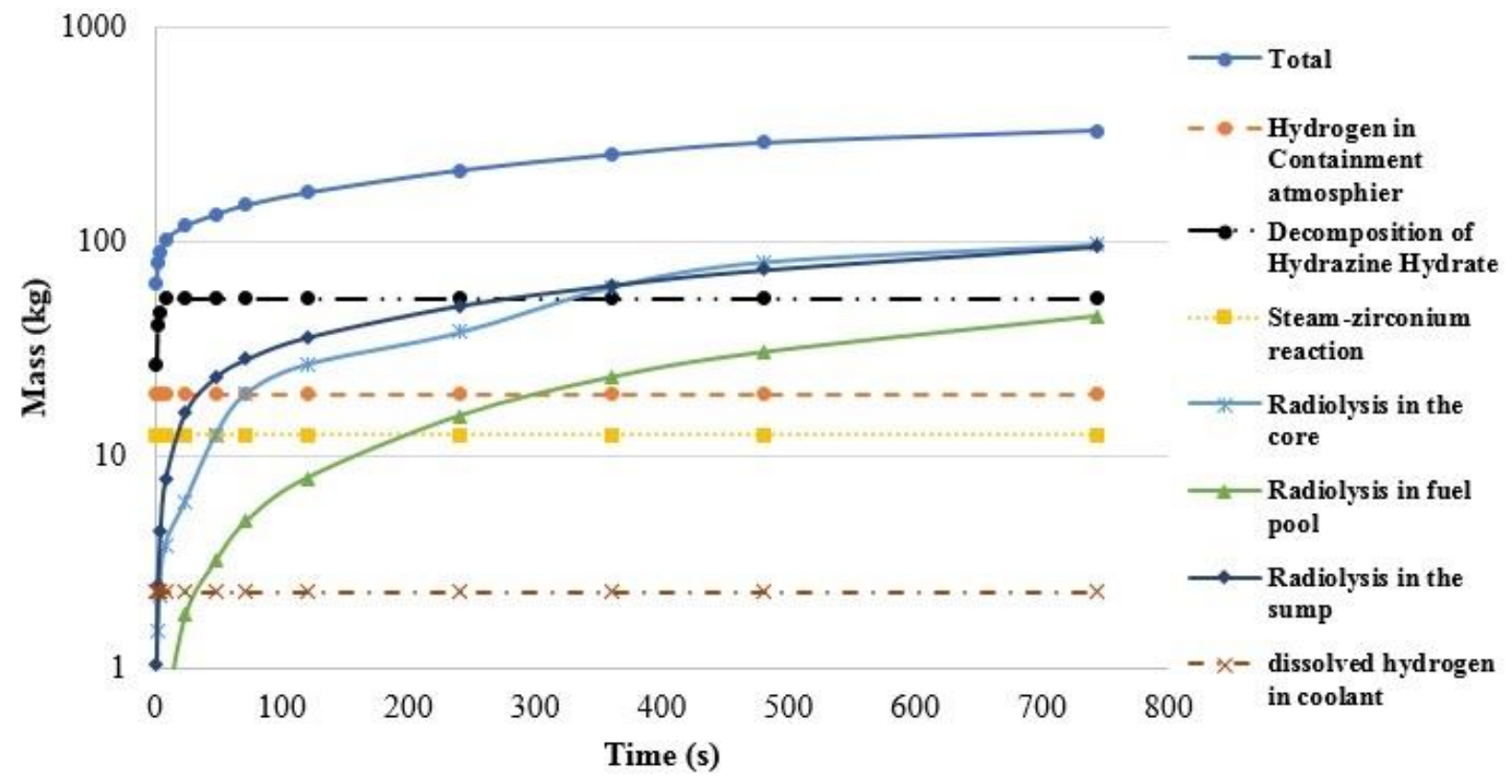

Figure 2. Hydrogen generation profile

\subsection{Hydrogen distribution and combustion}

Hydrogen distribution can be influenced significantly by some of the parameters such as containment layout, the location of hydrogen source, containment thermal-hydraulic conditions and rate of hydrogen release. Hydrogen can be released into the containment or reactor building through pathways and breaks of the Reactor Cooling System (RCS). 
Some of the engineering safety features like the spray system can also affect the distribution of hydrogen in containment. Spray systems are used in many NPPs to reduce the containment pressure, condense the steam, decrease the temperature and mitigation of hydrogen concentration. Spray system can decrease the risk of hydrogen accumulation and local detonations [25].

\subsection{Hydrogen control and risk mitigation}

Different methods and tools are using to control and mitigate the hydrogen concentration inside the containment, these are:

- pre-inertization by using some inert gas like Nitrogen

- mitigation by using Engineering Safety Features (ESFs) like spray, Passive Autocatalytic Hydrogen Recombiners (PARs) and igniters

One of the main advantages of passive autocatalytic hydrogen recombiners is that these safety features don't need to power source and actuation of the operator for their operation. The key point is to install these PARs in appropriate locations inside the containment to have more efficiency and coverage. Installation coordinates of PARs and their numbers are affected by the amount and distribution of hydrogen inside the containment, so analyzing the hydrogen distribution inside the containment can help to modify the using of these features.

\section{Loss Of Coolant Accident (LOCA) and its consequences}

DECL (Double Ended Cold Leg) is a specific type of LOCA with a complete break of cold leg pipe. It is one of the worst-case accidents in NPPs where the primary coolant is released to the containment leading to an increase of both pressure and temperature inside the containment. In addition, the amount of coolant in the core will reduce and the core temperatures increase in a 
manner that may conduct to the melting of the reactor core. There are three main stages to the time of the fuel rod failure as the LOCA accident progresses:

- Core uncover; the reactor level decreases because of loss of coolant through a break. The coolant inventory can leak very fast and the reactor pressure vessel depressurizes accordingly.

- Core boil-off; if the initial transient doesn't lead to blow down, the liquid level gradually drops as the decay heat vaporizes the water above and in the core.

- Core heat up; once the core is uncovered, fuel rods will heat up at a high rate. When the clad temperature reaches its melting point, cladding failure is assumed. As the temperature continues to rise, it will be reaching the temperature at which zircaloy/steam reaction produces hydrogen and more heat.

Table 4 shows the sequence of events when a LB-LOCA occurs in NPP.

Table 4. Events layout in LB-LOCA

Event

Time(sec)

Large break in the cold leg

0

Reactor scram

2

Start of accumulator

5

End of accumulator feed 65

Failure of cladding (cladding exceeds the temperature of 1,173 K)

Molten corium starts to form the molten pool

2,230

Dry core (no water in the active core)

2,790

Start of melt material slump in the lower head of the vessel

3,670

Pressure vessel failure

5,100

\section{Simulations}

\subsection{CONTAIN simulation code}

The CONTAIN 2.0 computer code is an integrated analysis tool to predict the physical condition, chemical composition and distribution of radiological materials inside a containment 
building following the release of material from primary system in a light water reactor accident [28]. Some of the CONTAIN models have been used in this simulation; inter-cell flow model, heat transfer structure model (walls, roofs, floors), lower cell model and engineering system model (spray, recombiner, heat exchanger).

\subsection{MELCOR simulation code}

MELCOR is a fully integrated computer code that can be used to simulate various phenomena in the progression of severe accidents inside the containment. These accidents that can be simulated by MELCOR are reactor coolant system thermal-hydraulic behavior in the case of accidents, reactor building and its cavity, containment and its relevant buildings and various process in the case of severe accidents. Different packages of MELCOR code have been used in this study such as control volume hydrodynamics, flow path, heat structures, containment spray and passive autocatalytic hydrogen recombiners [29].

\subsection{Simulation procedure}

Simulation of hydrogen distribution is conducted into two separate steps by using both CONTAIN 2.0 and MELCOR 1.8.6 to ensure validation of code inputs, geometry, and structure:

1. simulation of containment pressurization due to LOCA and analysis of the effectiveness of the spray system on thermal-hydraulic parameters of containment;

2. simulation of hydrogen distribution due to in-vessel hydrogen generation and effects of recombiners on its mitigation.

The total volume of Bushehr NPP containment is divided into 23 cells (control volumes in MELCOR). Each cell represents one or some connecting rooms and includes compartments of Bushehr NPP. The division of containment into these cells is considered according to the 
coordinate, included compartment and also their safety priority. Table 5 introduces the relevant specifications. Cells are connected together with 33 engineering vents (flowpath in MELCOR). Six of these are defined as valves in codes that are closed until the differential pressure between respective cells reaches $0.01 \mathrm{MPa}$ [25]. Cells layout diagram and connections are shown in Figure 3.

Table 5. Specification of containment cells

\begin{tabular}{cl}
\hline Cell number & Description of compartment \\
\hline 1 & Room for leakage collection \\
2 & Steam Generator (SG) compartment 1, pressurizer room, room of \\
3 & filters \\
4 & SG compartment 2, bubbler, room of filters \\
5 & Reactor vault \\
6 & Reactor vault, reactor internals pool \\
7 & Vault of the steam pipelines and feed water pipelines and the adjoining \\
& Rooms \\
8 & Vault of the steam pipelines and feed water pipelines and the adjoining \\
9 & Rooms \\
10 & Reactor Coolant Pump (RCP) room \\
11 & RCP room \\
12 & RCP room \\
13 & RCP room \\
14 & Fuel cooling pool, cask storage pool \\
15 & Fresh fuel storage facility \\
16 & Room of filtering installation and air recirculation \\
17 & Room of filtering installation and air recirculation \\
& Filtering system valve chambers \\
18 & Staircases and adjoining rooms under the fuel cooling pool, pumps of \\
& RCP oil cooling system. Chamber of process monitoring transducers. Pump \\
19 & of the oil cooler of the fourth loop. \\
20 & Staircases and adjoining rooms, chamber of the backup converter. \\
21 & Pumps of RCP oil cooling system, pipelines. \\
& Passage along the containment perimeter \\
& Room of the system high pressure cooler \\
& Reactor hall space inside the cylindrical wall \\
& Reactor hall space between the cylindrical wall \\
& Reactor hall space above the cylindrical wall \\
\hline
\end{tabular}




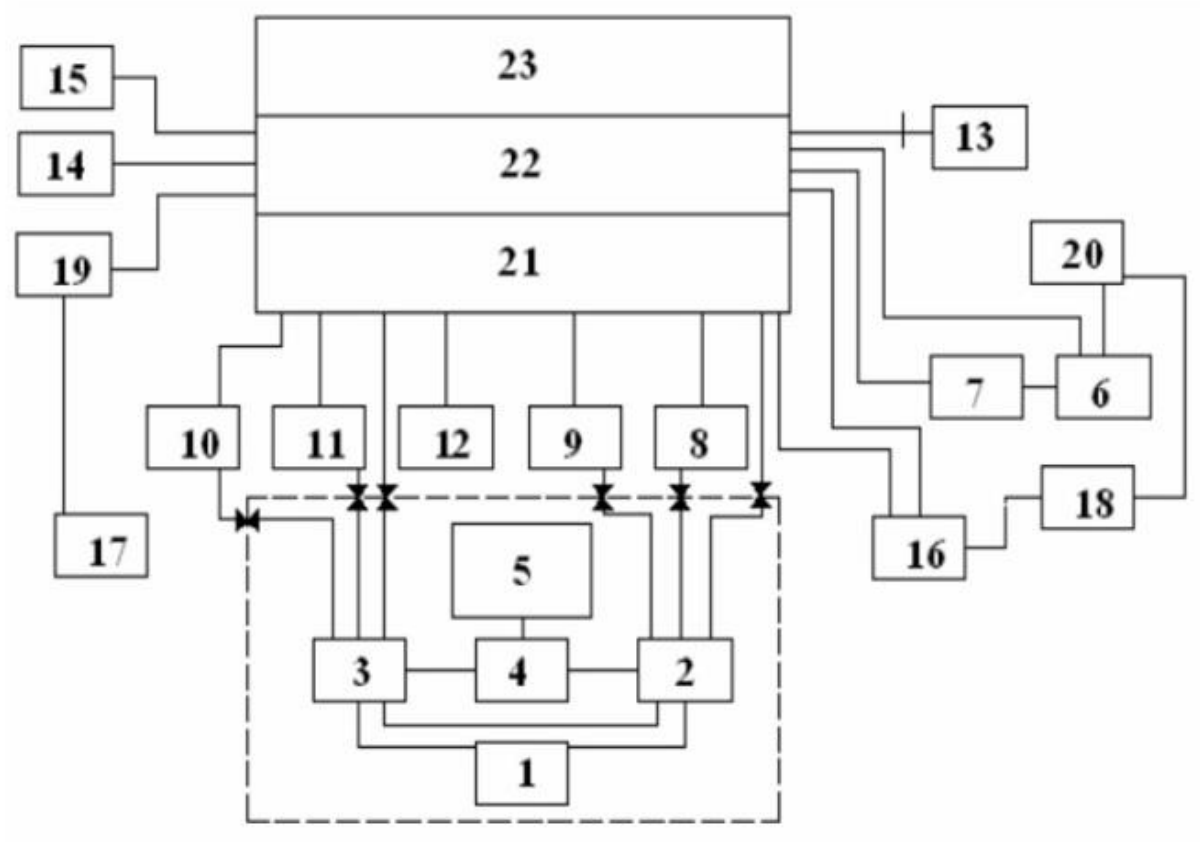

Figure 3. Cells layout diagram and connections

A set of 137 heat structures are also considered in the simulations, each characterized by its position, geometry, and type of structural material.

\subsubsection{Spray system}

The main purpose of the spray system as Engineering Safety Feature (ESF) is to reduce the temperature and pressure inside the containment in the case of accidents. If any accidents happen that lead to the release of water, steam or their mixture to the containment atmospheres, automatic actuation of spray system can reduce the temperature, pressure and concentration of radioactive isotopes by condensation on spray droplets and wash out the radioactive materials. The setpoint of actuation for BNPP's spray system is $0.03 \mathrm{MPa}$ gauge [25]. When the pressure inside the containment reduces to less than $0.02 \mathrm{MPa}$ (gauge), the spray system is disabled. The spray circuit is composed of pumps, valves, tanks, heat exchanger and nozzles that spray the coolant into the primary containment structure. Figure 4 shows the spray cycle in BNPP. 


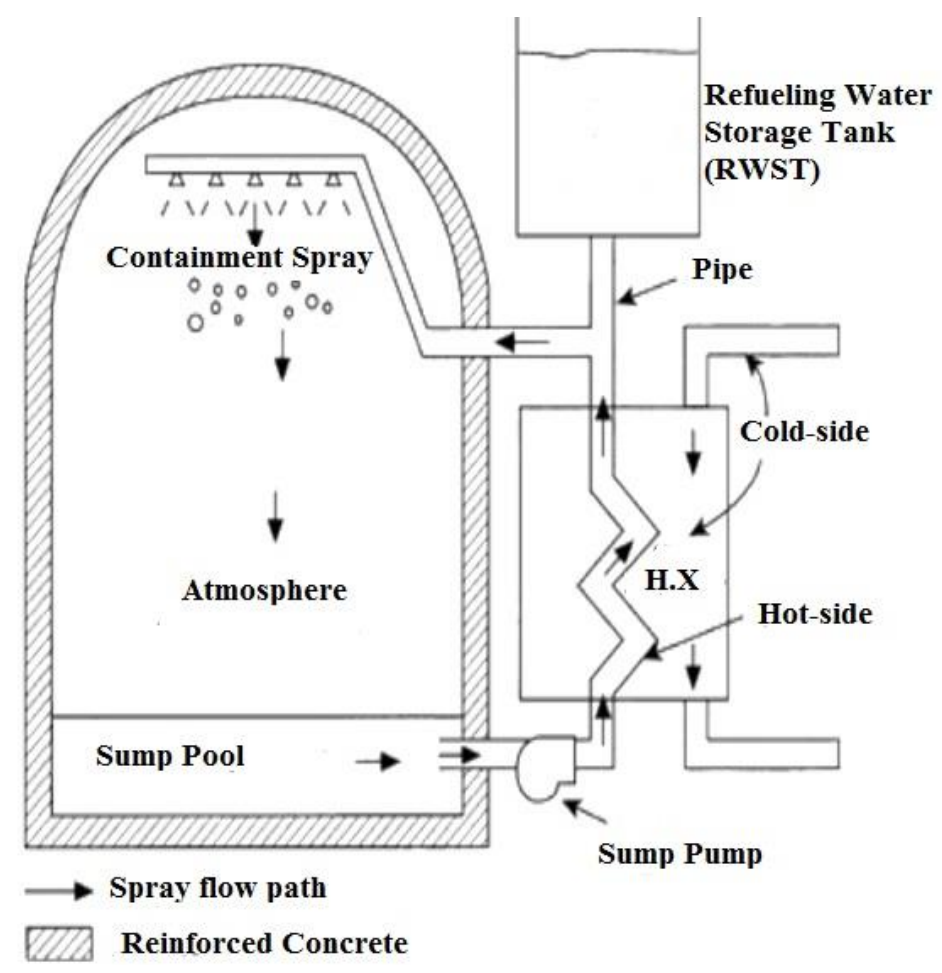

Figure 4. Spray cycle in BNPP

The spray system reduces the pressure and temperature inside the steel containment by injection of boric acid with concentration of $16 \mathrm{~g}$ boric acid $\left(\mathrm{H}_{3} \mathrm{BO}_{3}\right)$ per $1 \mathrm{~kg}$ water $\left(\mathrm{H}_{2} \mathrm{O}\right)$ and iodine-binding reagents. The temperature of this solution is in the range of $20-60{ }^{\circ} \mathrm{C}$ (depending to the situation) and its mass flow rate is 300 ton/hr. I. Table 6 lists the characterization of spray nozzles in BNPP spray system. Some of the characteristics of the spray nozzles are listed in Table 6.

Table 6. Characteristics of the spray nozzles

\begin{tabular}{ll}
\hline Characteristics & Value \\
\hline Materials sprayed by a nozzles & $\begin{array}{c}\text { Boric Acid solution } 16 \\
\mathrm{~g} / \mathrm{l}\end{array}$ \\
& Not more 90 \\
Temperature of sprayed materials, ${ }^{\circ} \mathrm{C}$ & 150 \\
Design temperature, ${ }^{\circ} \mathrm{C}$ & 0.1 \\
Pressure drop in nozzle, $\mathrm{MPa}$ & 31 \\
Flow rate of sprayed materials, $\mathrm{m}^{3} / \mathrm{h}$ & 75 \\
Angle of tapered solid cone of spraying, degree & 1.2 \\
Spraying dispersibility, mm & 50 \\
Conditional flow capacity of supplying pipe branch, mm & 30 \\
Conditional flow capacity of outlet pipe branch, mm & \\
\hline
\end{tabular}




\subsubsection{Description of hydrogen reduction system}

The containment hydrogen concentration monitoring system and the hydrogen removal system (named "XP" in FSAR [25]) are two components to control the concentration of hydrogen that may be released throughout the containment vessel atmosphere during a LOCA. Following the DBA, hydrogen gas may accumulate through the containment vessel from various sources. Whenever an adequate amount of hydrogen is generated, the reaction between the oxygen present in the containment vessel atmosphere and hydrogen produced may occur. Therefore, according to the consequences of LOCA, the indoor hydrogen concentrations in an Accident Localization Area (ALA) are preserved by the XP system according to flame-propagation limits of the parameters design range in the ALA rooms [25]. The components used in the emergency hydrogen removal system have been designed to operate successfully to maintain the maximum hydrogen concentration in the containment at or below $2 \%$ vol (volumetric) during LOCA and below $0.5 \%$ vol in the post-accident period. To avoid problems like nonuniform mixing, the former limit was selected as a reasonable limit [25]. The hydrogen monitoring system includes circumferential equipment to measure the volumetric hydrogen concentrations and to display and generate an alarm signal to the main control room (MCR) and emergency control room (ECR). Therefore, this emergency system shall be in function under all operating conditions, including the accident conditions [25]. One of the main components of the hydrogen removal system is the set of Passive Autocatalytic hydrogen Recombiners (PARs). PARs are located where the accumulation of hydrogen is possible [25]. A recombiner consists of:

- catalyst unit, consisting of a set of catalyst rods installed in the unit frame;

- frame (convective section with a protective shell);

- eyes for securing to embedded parts.

The XP system which is used in the Bushehr NPP consists of: 
- a collection of 32 detectors which are used to ensure that the hydrogen concentration monitoring system fulfills its functions specified by the requirements;

- a collection of 80 pieces of self-contained passive autocatalytic hydrogen recombiners that are used to ensure the emergency hydrogen disposal system fulfills the required functions.

Generally, a PAR is composed of a unit of catalysts, comprising a set of catalytically active components, the convection section, equipped with a protective housing, and a cantilever to fasten it to the embedded part. The operation principle of PAR is based on the catalytic recombining reaction of hydrogen with oxygen on the catalytic surface. Platinum group metals are used as the catalyst. RVK-500 [25] type recombiner (TU 002 RVK RET-2004) is one of the most common types of recombiner, designed to comply with the requirements imposed by the design-basis accident occurrence, in full measure. The technical data of the device are listed in Table 7, whereas a schematic is represented in Figure 5.

This component, which is installed in various parts of the containment, is simulated by the PARs (Passive Autocatalytic hydrogen Recombiners) model in the MELCOR code that is based on the Fischer model, which is a parametric one developed for the most common PAR design [29].

Table 7. Characteristics of RVK-500 passive catalytic hydrogen recombiner [25]

\begin{tabular}{|lc|}
\hline Characteristic & Value \\
\hline Overall dimensions: & $950 \pm 5$ \\
- height, mm & $226 \times 334^{ \pm 5}$ \\
- dimension in plan, mm & 25 \\
\hline Mass, kg, not more than & \\
\hline
\end{tabular}


Specific capacity for recombined hydrogen, $\mathrm{kg} /\left(\mathrm{m}^{2} \cdot \mathrm{s}\right)$ (capacity related to the area of convective section of the shell at $0.2 \mathrm{MPa}$ and $100{ }^{\circ} \mathrm{C}$ ):

- when the volumetric concentration of $\mathrm{H}_{2}$ is $3 \%$

- when the volumetric concentration of $\mathrm{H}_{2}$ is $5 \%$

- when the volumetric concentration of $\mathrm{H}_{2}$ is $8 \%$

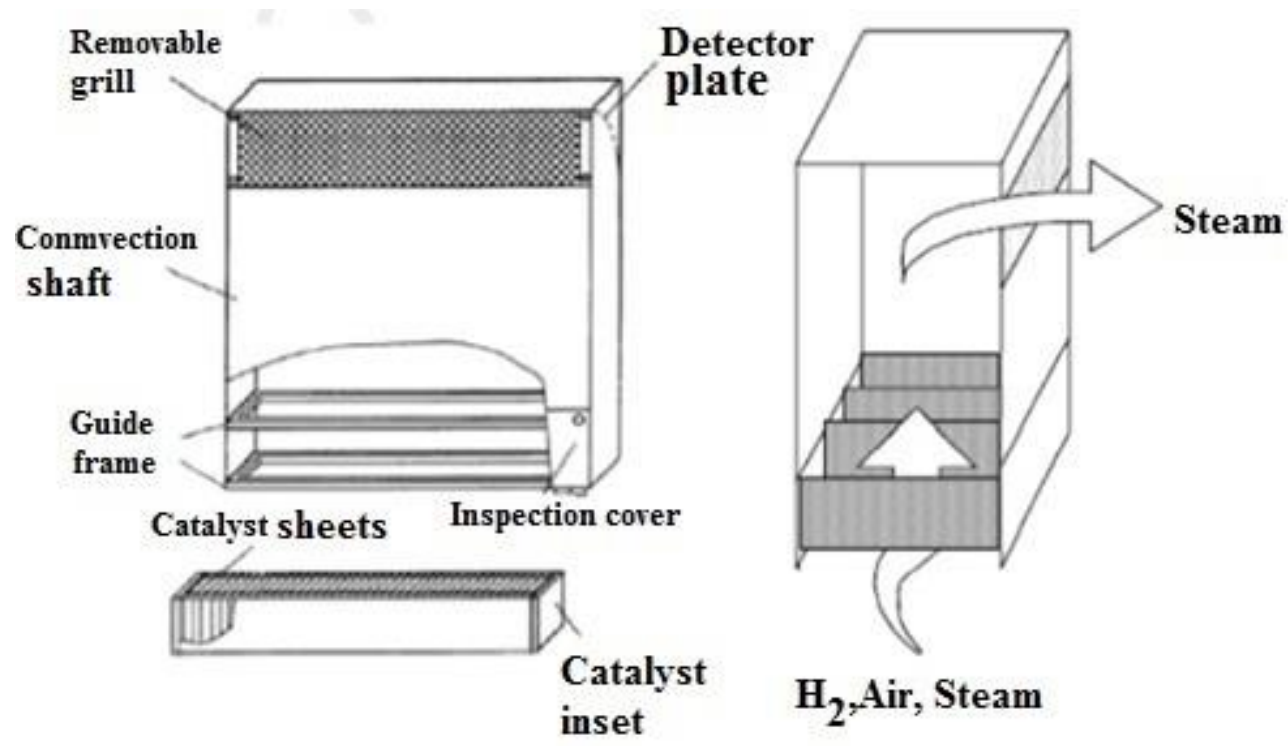

Figure 5. Passive autocatalytic hydrogen recombiner

\subsubsection{Simulation conditions}

During the simulations, some assumptions are considered. The initial pressure of containment is equal to atmospheric pressure (around $0.098 \mathrm{MPa}$ ). Temperatures in the cells located in the center of containment (cells 8, 9, 10 and 11) are selected as $60^{\circ} \mathrm{C}$ [25], for other cells these equal $30{ }^{\circ} \mathrm{C}$. Some other parameters of the initial conditions are given in Table 8 . 
Table 8. Initial conditions for DECL accident

\begin{tabular}{ll}
\hline \multicolumn{1}{c}{ Parameter } & Value \\
\hline Initial power $(\mathrm{MW})$ & 3,120 \\
The design pressure inside the containment $(\mathrm{MPa})$ & 0.46 \\
Initial pressure in the primary system $(\mathrm{MPa})$ & 15.7 \\
Initial pressure in the secondary side $(\mathrm{MPa})$ & 7.0 \\
Located of rupture is in the reactor inlet & Loop 4 \\
Located of rupture point & Cell 3 \\
The spray system flow rate $(\mathrm{kg} / \mathrm{s})$ & 83.33 \\
Number of high pressure injection coolant pumps $(\mathrm{design})$ & 1 \\
Number of low pressure injection coolant pumps $(\mathrm{design})$ & 1 \\
Period of spray system operation $(\mathrm{s})$ & 1800 \\
Water temperature in borated water storage tanks $\left({ }^{\circ} \mathrm{C}\right)$ & 60 \\
\hline
\end{tabular}

Pipeline break is assumed in cell number 3. Figure 6 and 7 show the profiles of mass and energy that are injected into cell 3 due to break, respectively. These data are used as code input in cell 3.

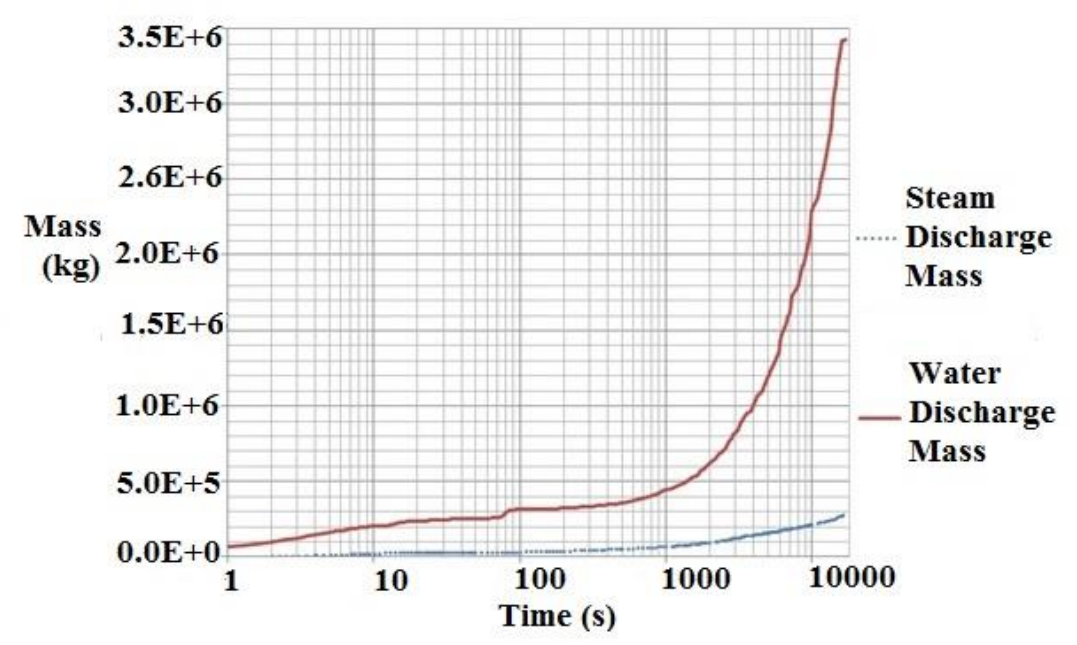

Figure 6. Profile of mass release from break [25] 


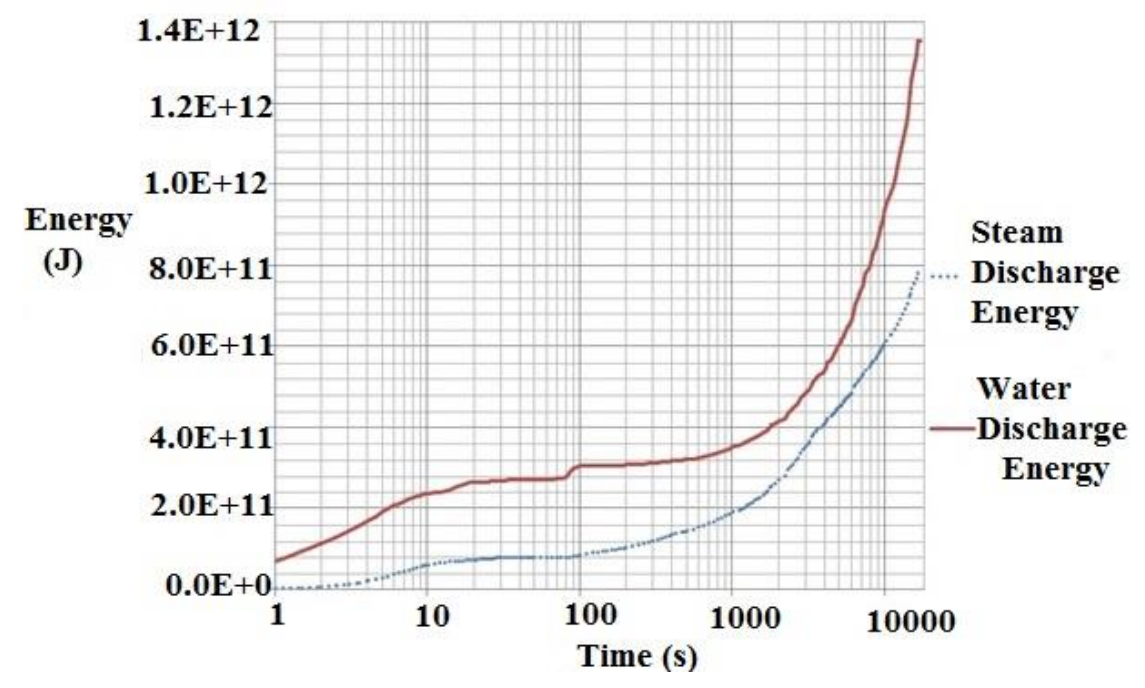

Figure 7. Profile of energy release from break [25]

Time steps of simulation codes (CONTAIN and MELCOR) are considered according to the priority of outputs details in the respective time range. Table 9 lists time steps that are used in codes in different time ranges.

Table 9. Codes time steps in the different time ranges

\begin{tabular}{|lllll|}
\hline Accident Time Range (s) & $0-25$ & $25-200$ & $200-50000$ & $50000-3600000$ \\
\hline Time Step (s) & 0.01 & 0.02 & 0.05 & 0.1 \\
\hline
\end{tabular}

Condensation process is activated in 23 cells by using "condense" instruction in CONTAIN code, the default value $(\mathrm{ICOND}=0)$ is also considered in MELCOR code that means condensation of water onto all aerosol particle is evaluated.

\section{Results and discussion}

Results of simulations related to thermal-hydraulic parameters in short time (0-200 seconds) and long time ( $0-10^{5}$ seconds) are now presented. Effects of spray actuation are considered in short time. Hydrogen distribution and effects of PARs on its mitigation are also simulated in long time. 
Pressurization of containment is almost a uniform process compared with temperature rising in different cells. Pressurization is affected more by adding of steam and water mass to the containment while temperature increases more by heat up (supply of energy) that is a slower process and depends on the components of each cell. Therefore, the pressure profile is almost similar in different cells. Figure 8 shows the average pressure profile in short time where it can be clearly noticed the effects of spray in reducing the average pressure. The peak pressure is about $0.4 \mathrm{MPa}$ that is lower than $0.46 \mathrm{MPa}$ as the maximum design pressure. It should be also noted that the maximum pressure with actuation of ESFs occurs after $20 \mathrm{~s}$, showing the importance of the short time accident analysis. Long time average pressure profile is displayed in Figure 9, where the effectiveness of continuous working of spray and condensation of steam on spray drops in decreasing the pressure value can be perceived.

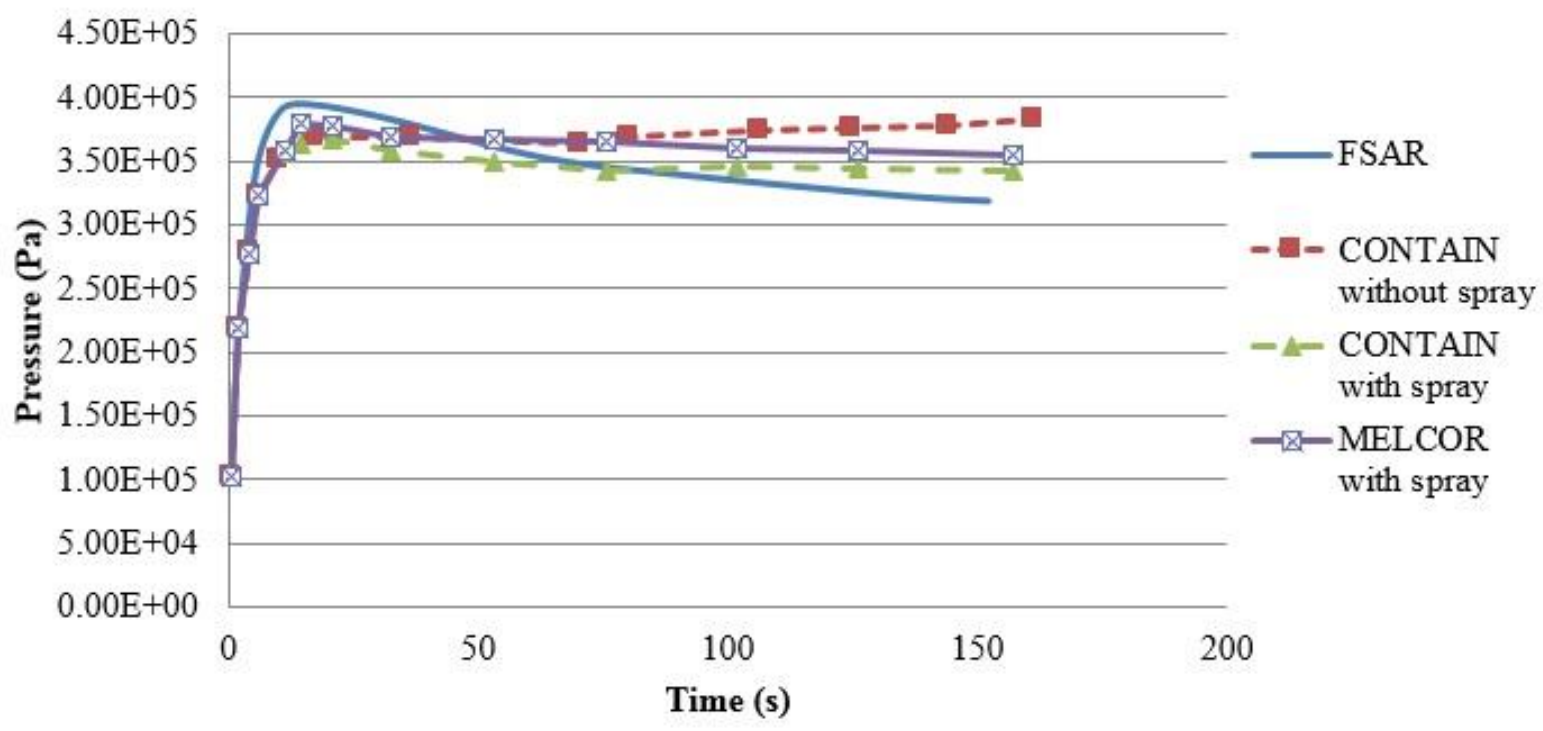

Figure 8. Short term average pressure profile 


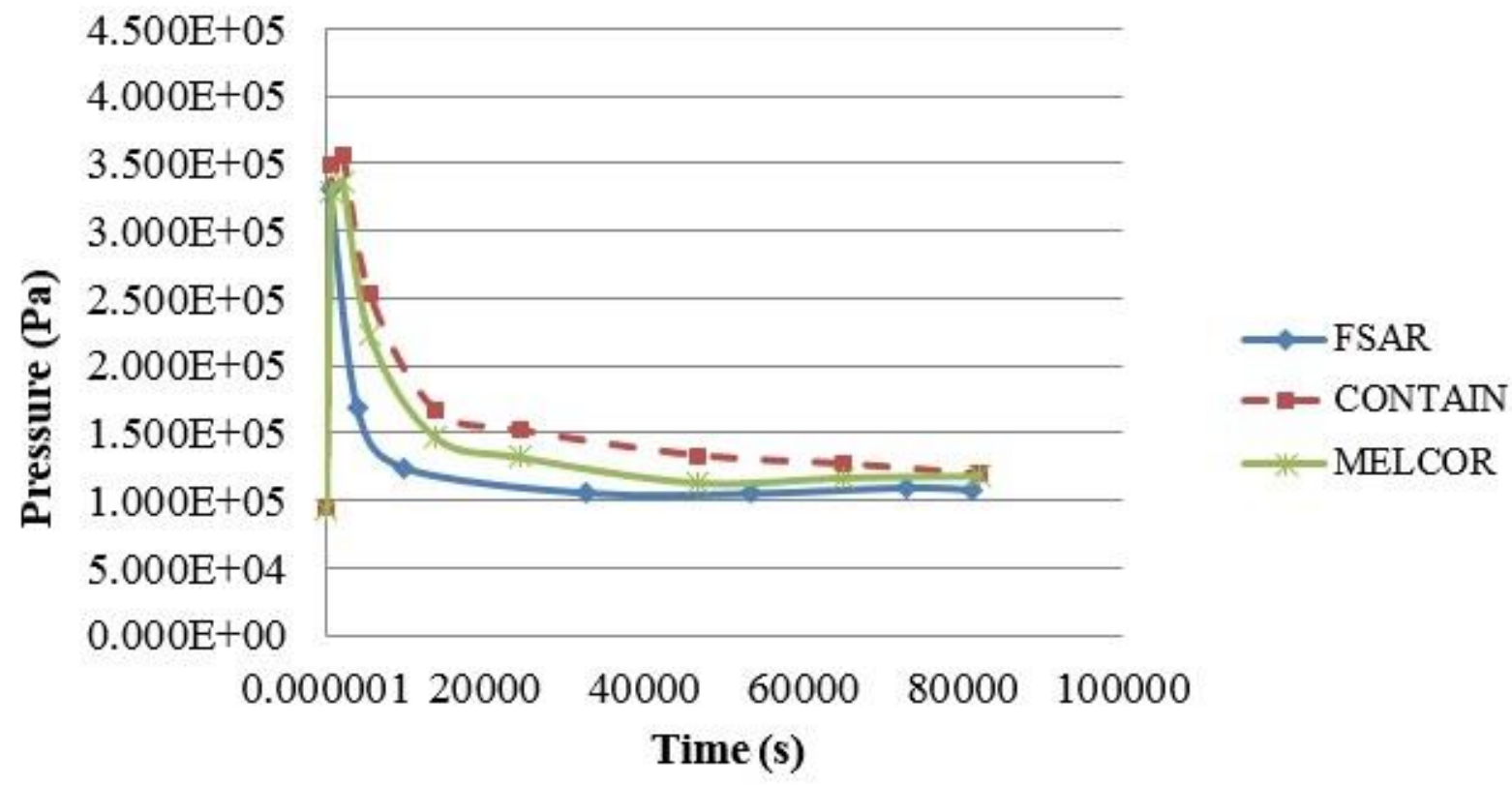

Figure 9. Long term average pressure profile

Results related to temperature and hydrogen distribution profiles are here shown for four representative cells (i.e. $3,18,22$ and 23 ) out of the 23 in which the containment volume is divided (cells location and compartment can be found in Table 5). Figures 10 to 13 display the temperature profiles and the effect of spray for the selected cells in short time. In all of them, on the initial 20 seconds of the accident, the temperature rises suddenly up to its maximum point (spray has activated reaching its pressure set point after $5 \mathrm{~s}$ ). After a while, due to condensation of steam on spray droplets, the temperature decreases with a low slope demonstrating the reliability of the spray system in mitigating the consequences of this accident. Even though the plots are qualitatively similar, different temperature values are obtained for different cells because of their connections (inlet and outlet vents), location and heat structures. The results agree quite well with the FSAR data. 


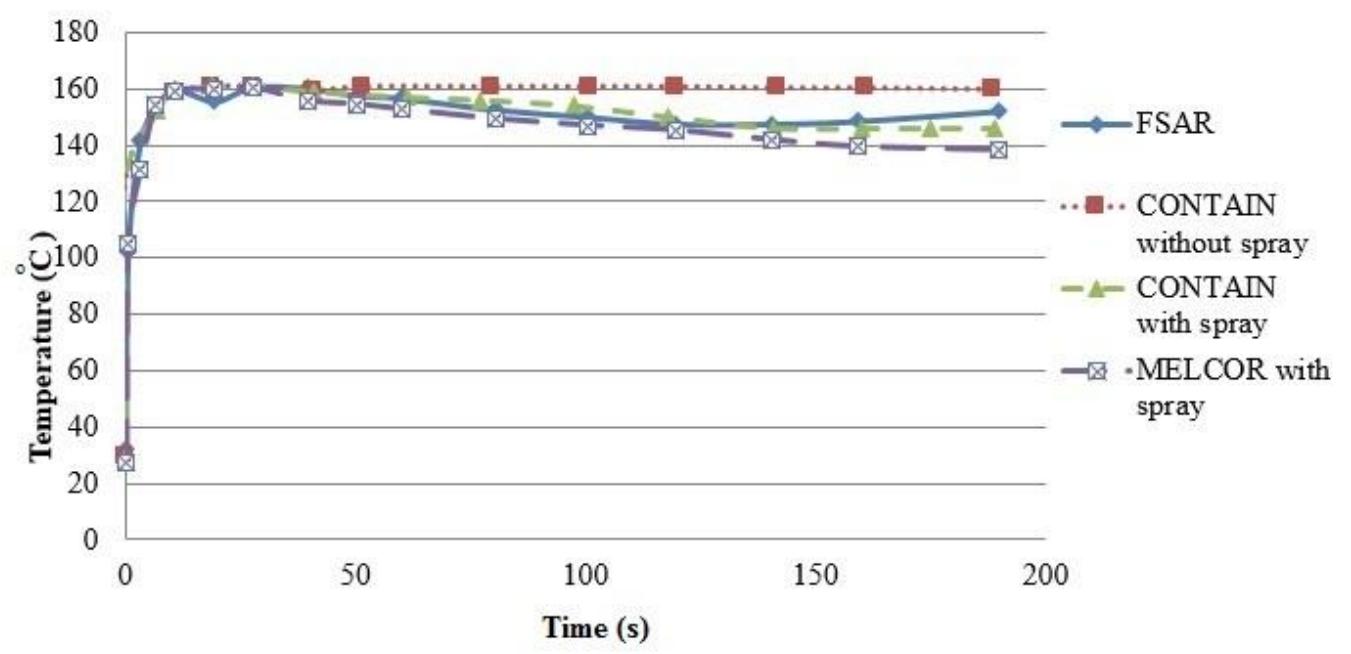

Figure 10. Short term temperature profile of cell 3 (SG compartment 2, bubbler, room of filters)

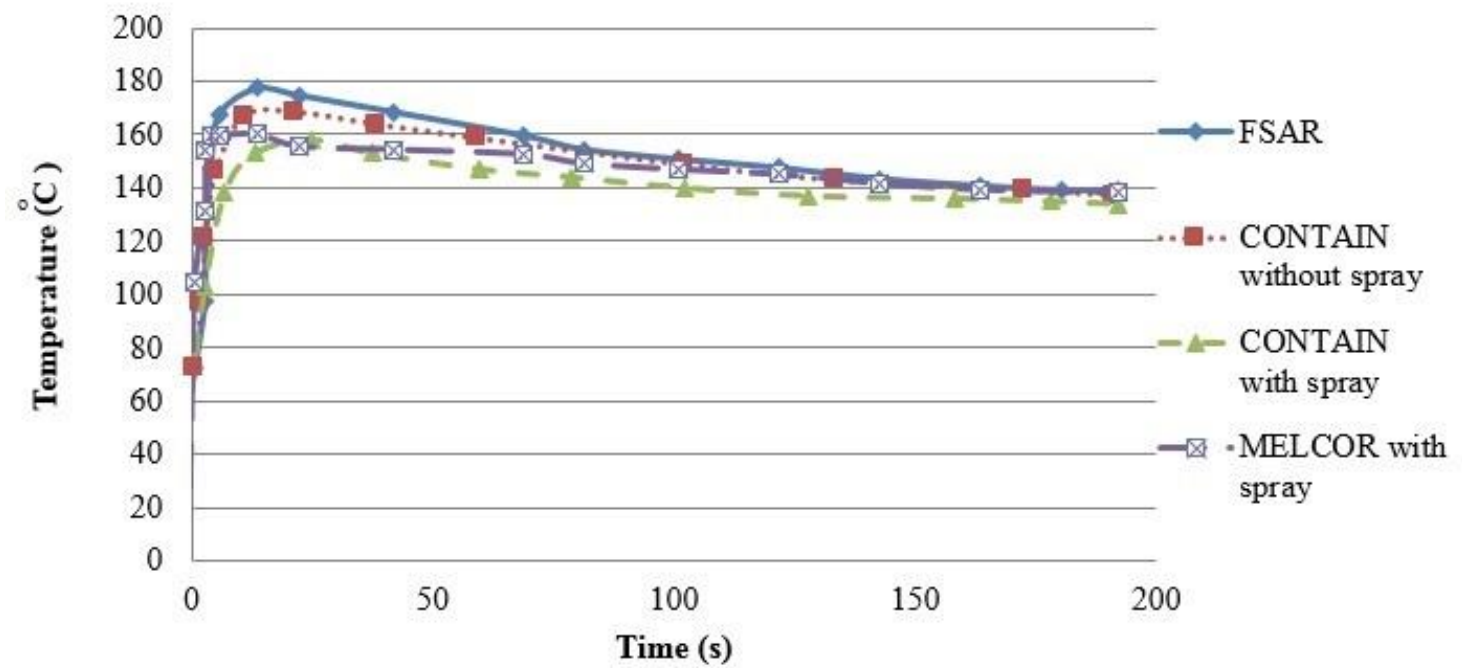

Figure 11. Short term temperature profile of cell 18 (Staircases and adjoining rooms, chamber of the backup converter. Pumps of RCP oil cooling system, pipelines.) 


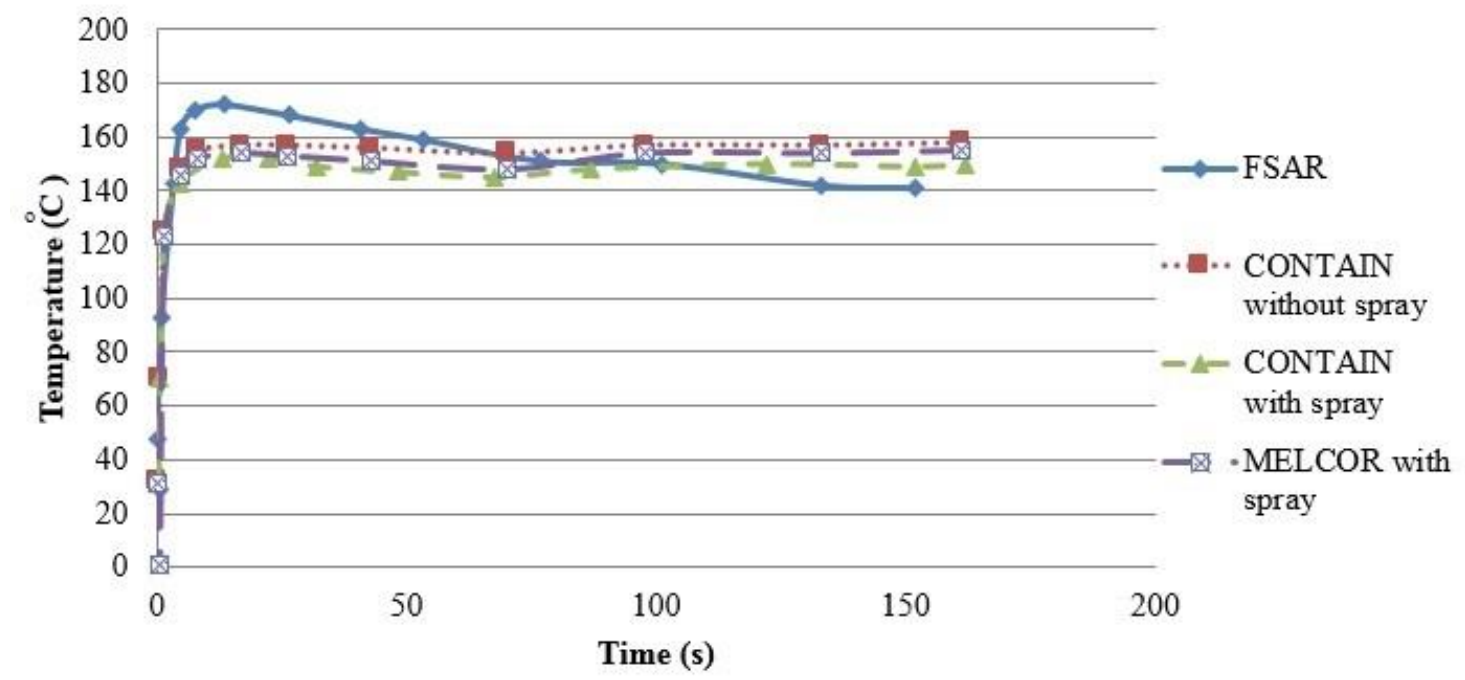

Figure 12. Short term temperature profile of cell 22 (Reactor hall space between the cylindrical wall)

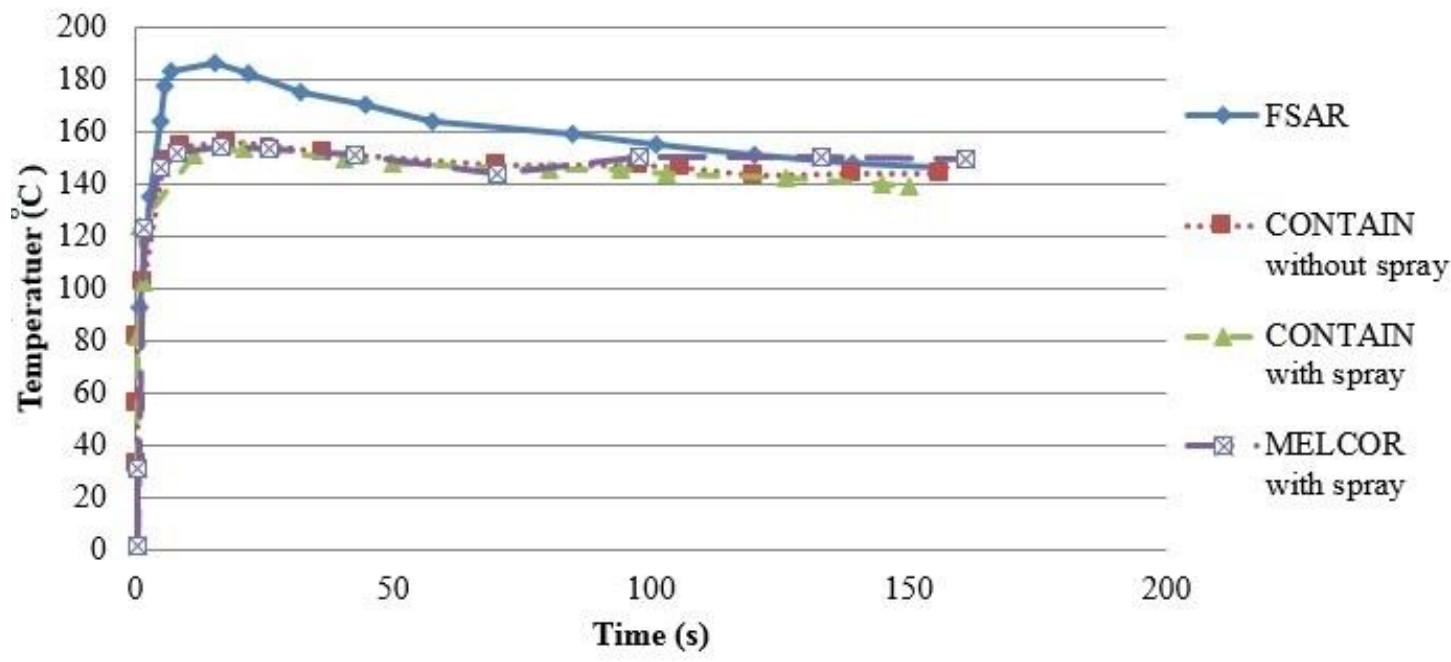

Figure 13. Short term temperature profile of cell 23 (Reactor hall space above the cylindrical wall)

For a better understanding of the hydrogen distribution, the profile of hydrogen mole fraction versus time for each of four selected cells in the long time is shown alongside its relevant temperature profile, both in the same figure. Each profile is plotted up to the time (reported on the abscissa) after which a steady-state behavior is recovered. These times are $10^{5}$ and $3.6 \times 10^{5}$ seconds (corresponding to $1000 \mathrm{hrs)} \mathrm{for} \mathrm{temperature} \mathrm{and} \mathrm{hydrogen} \mathrm{mole} \mathrm{fraction,} \mathrm{respectively.}$ 
Figures 14 to 17 show the hydrogen distribution profiles, with and without recombiner actuation, and temperature profiles for cells 3, 18, 22 and 23, respectively. As the effects of recombiner on hydrogen distribution are almost the same for CONTAIN and MELCOR codes, only those computed with the latter are reported. In the initial times of accident, there is a low concentration of hydrogen inside the containment cells. As discussed before (Table 3), these amounts of hydrogen are due to the containment atmosphere in STP (Standard Temperature and Pressure) condition and radiolysis of water in the fuel pool. As breakage occurs, the spontaneous injection and flashing of the water and steam mixture into containment leads to an instantaneous increase of water and steam mole fraction in each cell and a coincident reduction of the hydrogen mole fraction. Along the progress of the accident, due to the creation of new hydrogen generation sources (such as steam-zirconium reaction) and spray actuation, the mole fraction of hydrogen increases. As PARs set points are around 1.5\% vol, at this concentration PARs are activated. As it can be seen in these figures, using the PARs can prevent from rising the hydrogen concentration up to $2 \%$ that is flame propagation limit [25]. Results are in good agreement with the FSAR data (ANGAR code) showing the accuracy of the simulations. Discrepancies are due to different models and methods implemented into the three codes, ANGAR simulation method, number of heat structures and definition of code inputs. Although both CONTAIN and MELCOR codes solve conservation equations inside control volumes, their results are slightly dissimilar as their computational assumptions are not exactly the same, being the differences related to the number of conservation equations employed to the model coolant, liquid phase treatment models, number of enclosures, and number of the flowpaths between enclosures.

Finally, the hydrogen mole fraction (without recombiner actuation) and thermal-hydraulic distribution maps are presented in Figure 18 for the last seconds of long time accident (about $10^{5}$ seconds). Cell 20 has the maximum mole fraction in the long-term, about $9.3 \%$ in the 
absence of PARs, whereas the maximum amount of hydrogen is found in cell 22 (not reported in the figure). By activating the PARs at their set point (1.5\%vol), as seen in Figure 14 to 17, the concentration drops below the flame propagation limit.
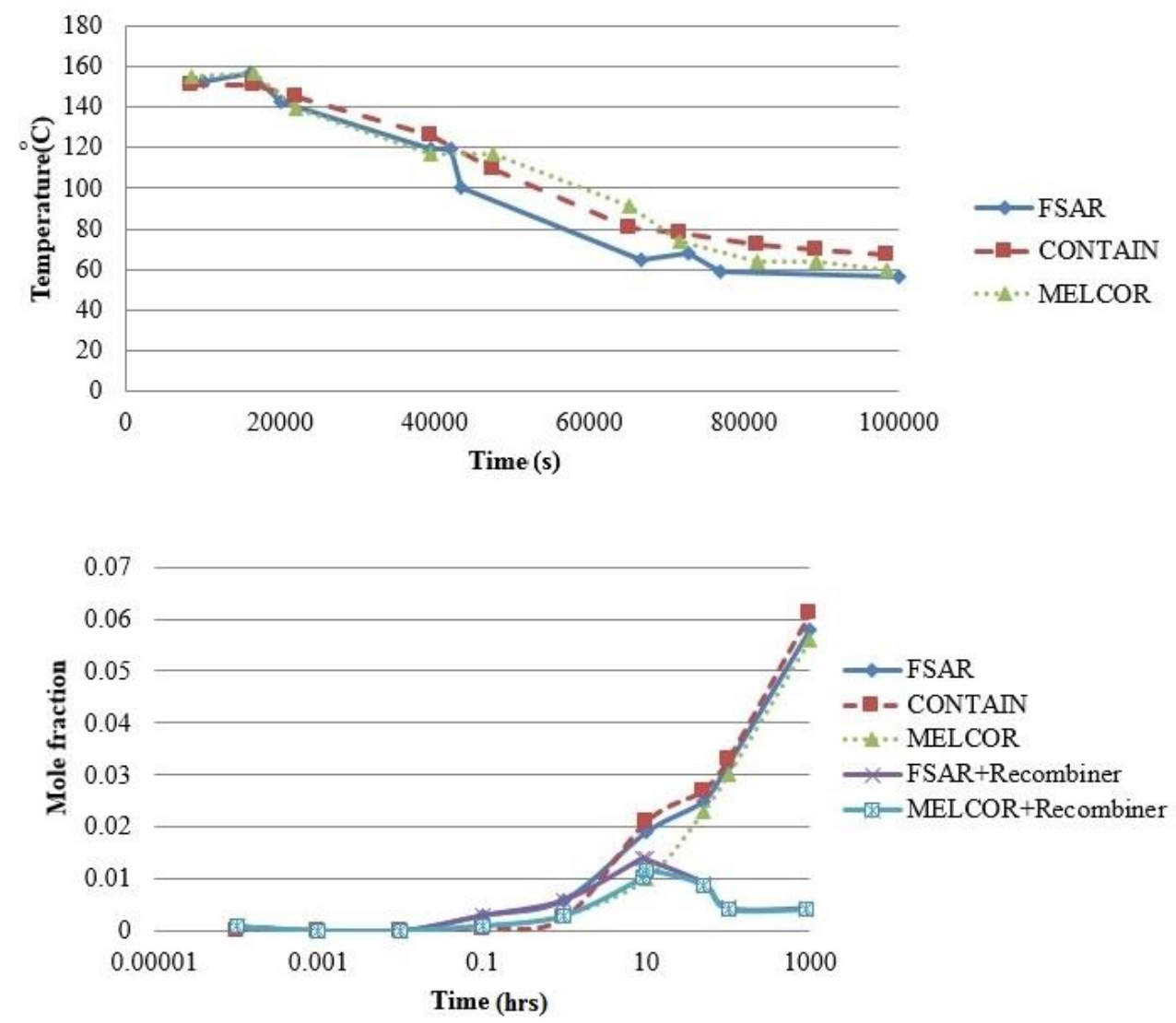

Figure 14. Hydrogen distribution profile in cell 3 

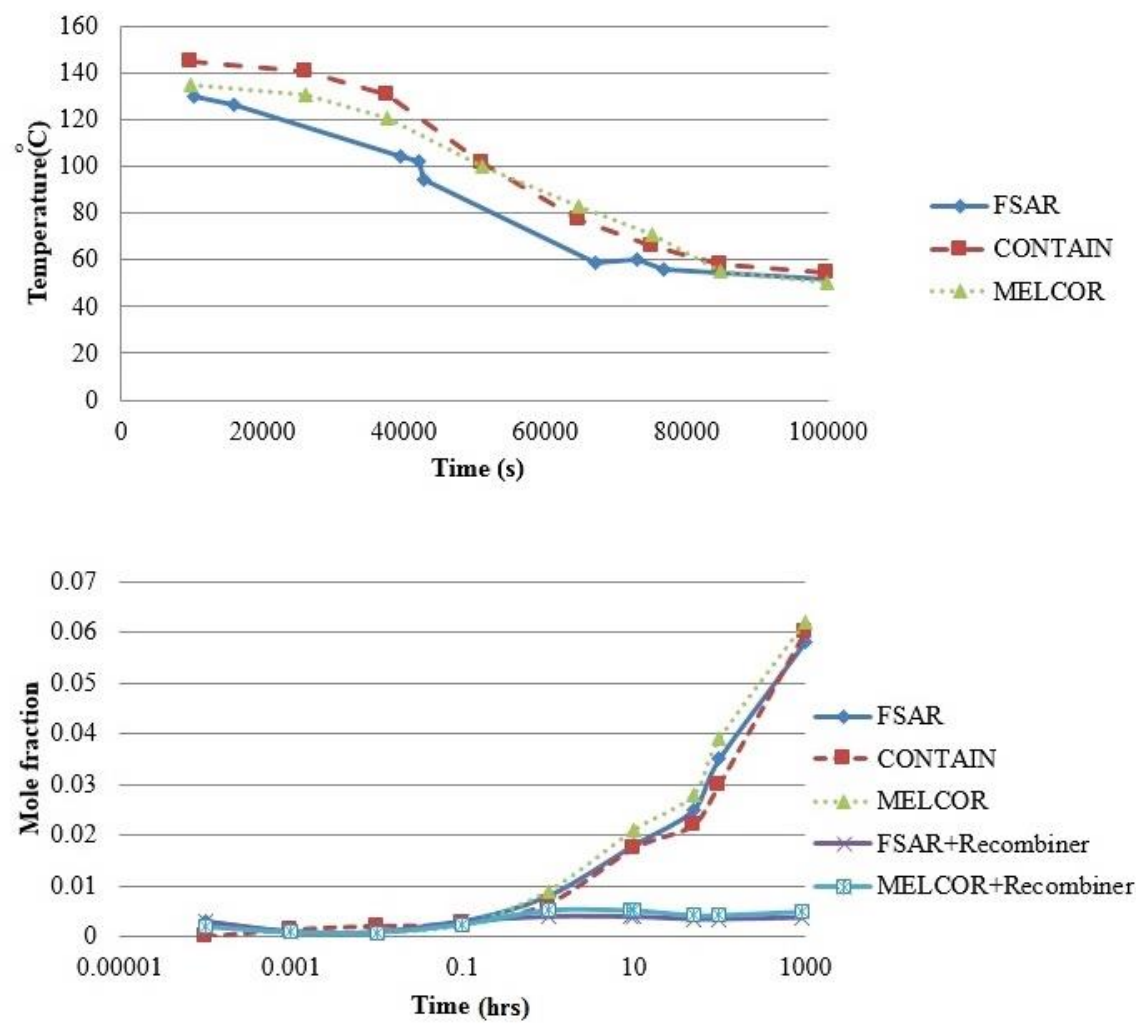

Figure 15. Hydrogen distribution profile in cell 18
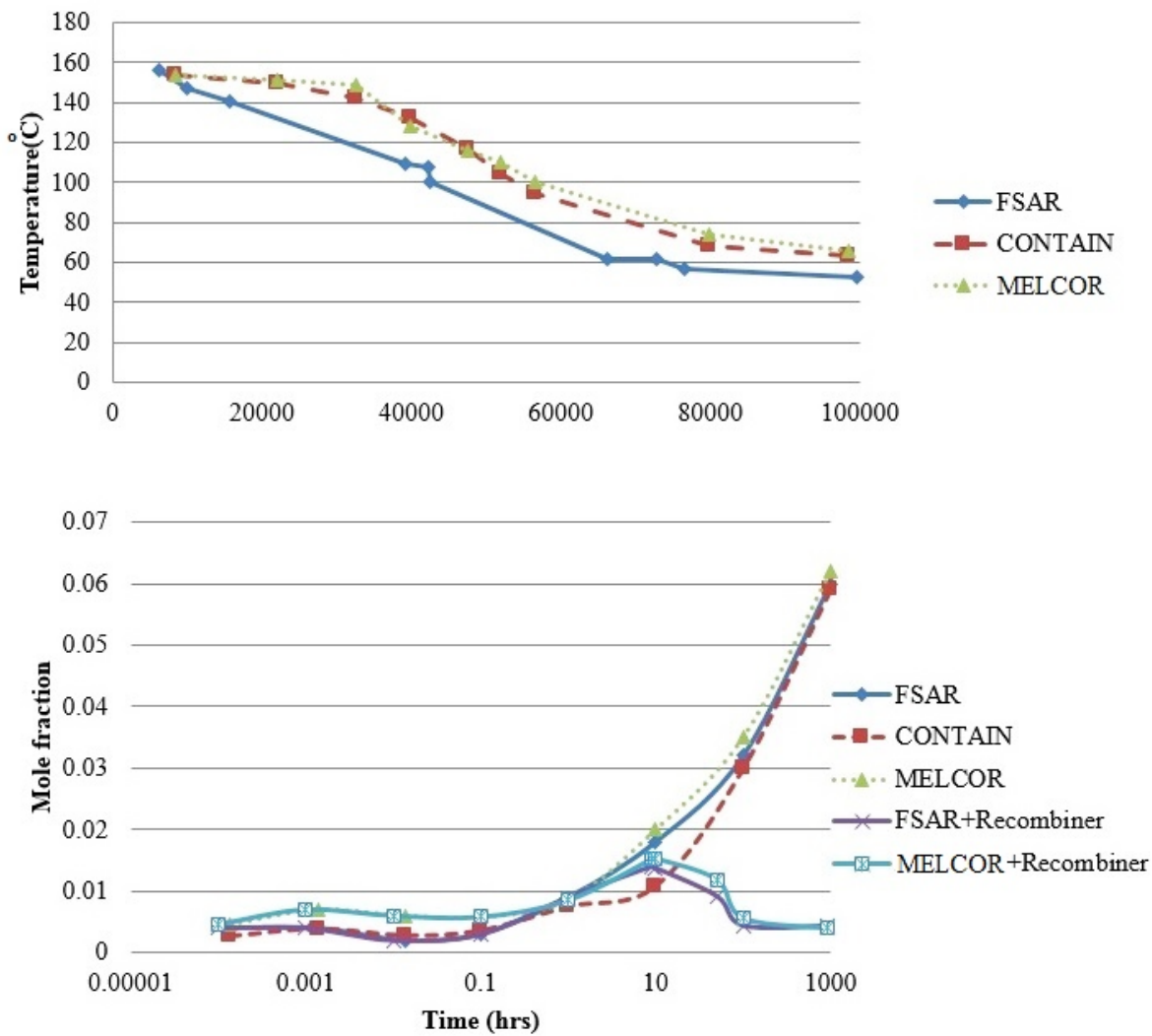

Figure 16. Hydrogen distribution profile in cell 22 

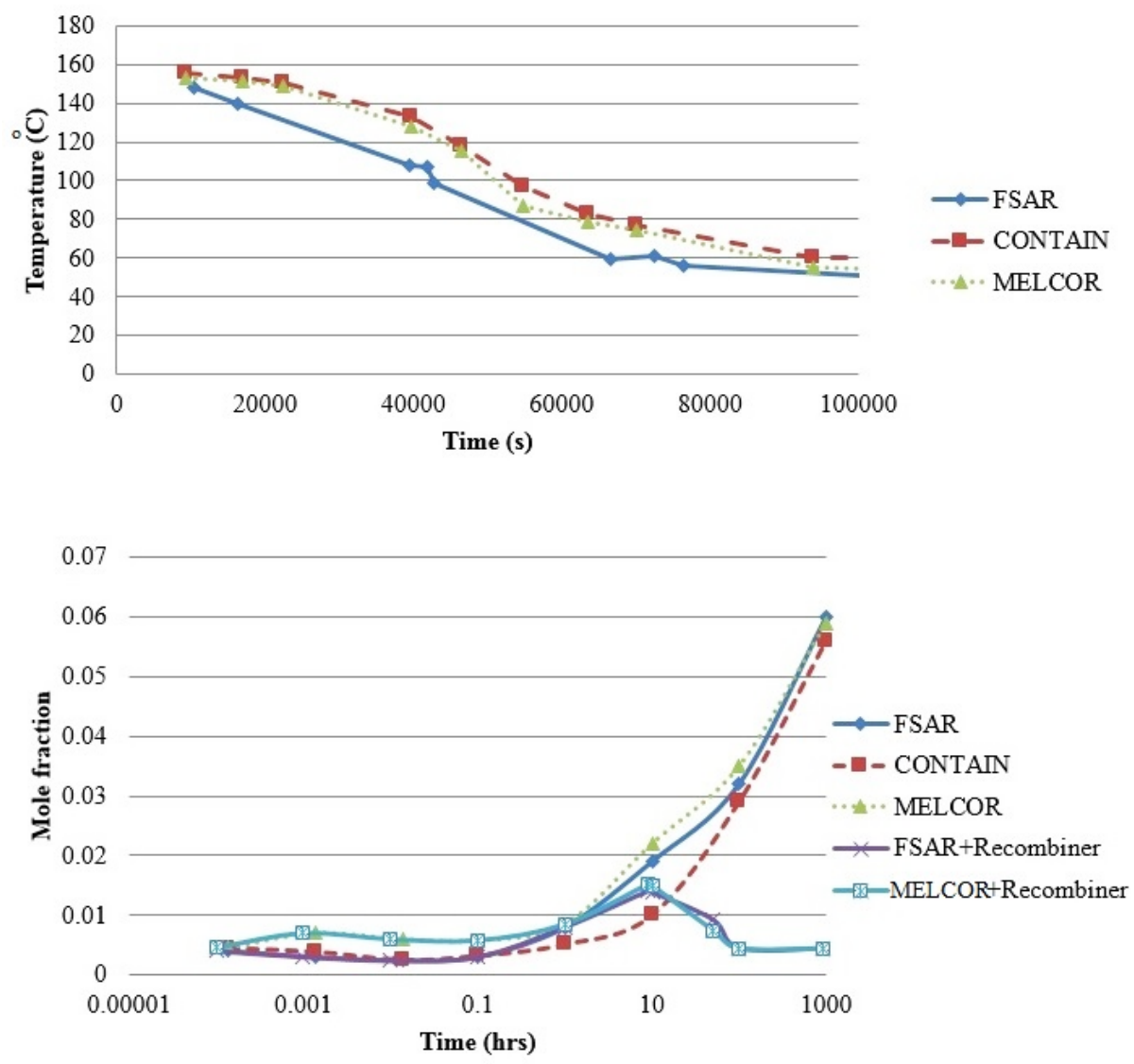

Figure 17. Hydrogen distribution profile in cell 23.

\section{Conclusion}

Monitoring the hydrogen concentration inside the containment is one of the main safety measurements in the case of BDBA and severe accident. Hydrogen accumulation and its explosion inside the containment can put the integrity of containment in danger and eventually lead to the release of radioactive material to the environment.

In this paper, distribution of hydrogen due to the in-vessel severe accident has been simulated by using CONTAIN 2.0 and MELCOR 1.8.6 codes. Thermal-hydraulic parameters of containment (temperature and pressure), spray effects on these parameters, the mole fraction of hydrogen and PARs effects on mitigation of hydrogen concentration have been simulated in short and long times and compared with those reported on the FSAR (ANGAR code). The outcomes show that: 
- in the presence of ESFs, the pressure and temperature peaks occur in the initial seconds of this type of accidents. Therefore, actuation of some ESFs (like spray) in the initial seconds of the event can keep the thermal-hydraulic parameters below their maximum design value, playing a vital role in decreasing the accident consequences and avoiding the disintegration of containment.

- Recombiners as a type of ESF can reduce the hydrogen concentration below the flame propagation critical limit in the accidents where hydrogen generation takes place. Their efficiency depended on their specifications, their number and locations inside the containment that show the importance of the knowledge of hydrogen distribution during the accident. This knowledge can help the engineers to correctly locate the recombiner units within the power plant layout.

- MELCOR, CONTAIN and ANGAR [25] codes relate to the class of multi-parametric codes with lumped parameters and are designed for numerically analyzing the development of accident in NPP containments. The observed discrepancies are because of the different models, numerical methods, solution algorithm, properties library and different assumptions that these codes are using in their simulations.

\section{Acknowledgments}

Part of this research has been developed under the auspices of EU H2020 Union's Horizon 2020 research and innovation programme Marie Skłodowska-Curie Actions COFUND grant SIRCIW, agreement no. 663830 . 


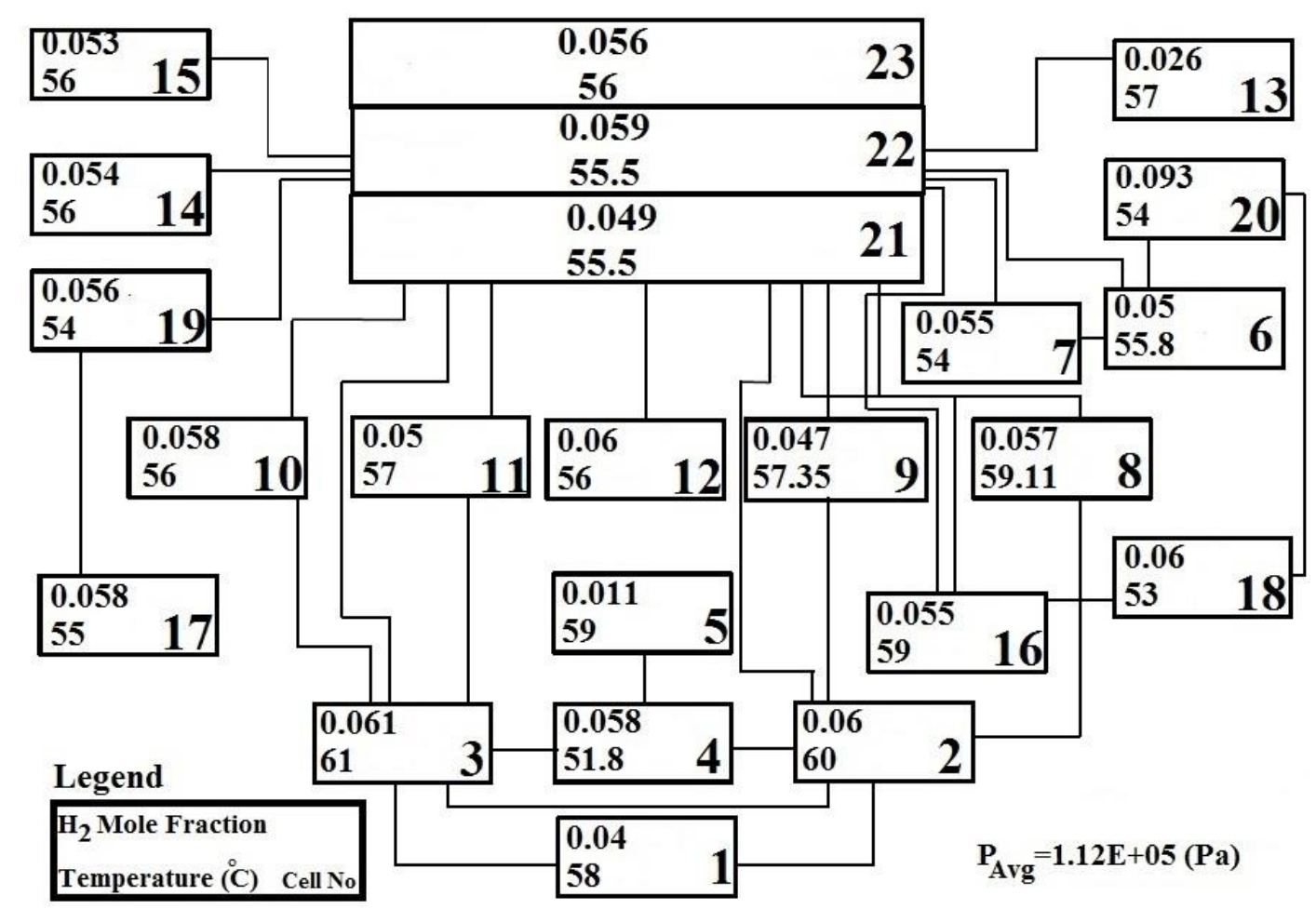

Figure 18. Hydrogen and thermal-hydraulic distribution map in last second of accident (about $10^{5}$ seconds) 


\section{References}

[1] J.N. Sorensen, G.E. Apostolakis, T.S. Kress et al., On the Role of Defence in Depth in Risk-Informed Regulation. Washington D.C, 1999.

[2] O. Noori-Kalkhoran, M. Rahgoshay, A. Minuchehr et al., Analysis of thermalhydraulic parameters of WWER-1000 containment in a large break LOCA. Ann. Nucl. Energy. 68, 101-11(2014). doi: 10.1016/J.ANUCENE.2014.01.009

[3] IAEA, Mitigation of Hydrogen Hazards in Severe Accidents in Nuclear Power Plants.Vienna, 2011.

[4] NRC, U.S. Nuclear Regulatory Commission Regulations: Title 10,Code of Federal Regulations.

[5] O. Noori-Kalkhoran, A. Minuchehr, M. Rahgoshay et al., Short-term and long-term analysis of WWER-1000 containment parameters in a large break LOCA. Prog. Nucl. Energy. 74, 201-212 (2014). doi: 10.1016/J.PNUCENE.2014.03.007

[6] O. Noori-Kalkhoran, A.S. Shirani, R. Ahangari, Simulation of Containment Pressurization in a Large Break-Loss of Coolant Accident Using Single-Cell and Multicell Models and CONTAIN Code. Nucl. Eng. Technol. 48, 1140-1153 (2016). doi: 10.1016/J.NET.2016.03.008

[7] D. Papini, D. Grgić, A. Cammi et al., Analysis of different containment models for IRIS small break LOCA, using GOTHIC and RELAP5 codes. Nucl. Eng. Des. 241, 1152-1164 (2011). doi: 10.1016/j.nucengdes.2010.06.016

[8] Y.S. Chen, Y.R. Yuann, L.C. Dai, Lungmen ABWR containment analyses during short-term main steam line break LOCA using GOTHIC. Nucl. Eng. Des. 247, 106115 (2012). doi: 10.1016/j.nucengdes.2012.02.012 
[9] G. Jimenez, C. Serrano, E. Lopez-Alonso et al., BWR Mark III containment analyses using a GOTHIC 8.0 3D model. Ann. Nucl. Energy. 85, 687-703 (2015). doi: 10.1016/j.anucene.2015.06.025

[10] Z. Huang, W. Ma, Performance evaluation of passive containment cooling system of an advanced PWR using coupled RELAP5/GOTHIC simulation. Nucl. Eng. Des. 310, 83-92 (2016). doi: 10.1016/j.nucengdes.2016.10.004

[11] EPRI, GOTHIC “Thermal Hydraulic Analysis Package Installation and Operations Manual", 2016.

[12] M. Povilaitis, S. Kelm, E. Urbonavičius, The Generic Containment SB-LOCA accident simulation: Comparison of the parameter uncertainties and user-effect. Ann. Nucl. Energy. 106, 1-10 (2017). doi: 10.1016/j.anucene.2017.03.037

[13] B. De Boeck, Prevention and mitigation measures to ensure containment integrity. Nucl. Eng. Des. 209, 147-154 (2001). doi: 10.1016/S0029-5493(01)00397-1

[14] S. Yu, M. Yan, J. Wang et al., Numerical investigations on the response of the passive containment cooling system and containment under a DELB LOCA scenario. Prog. Nucl. Energy. 97, 26-37 (2017). doi: 10.1016/j.pnucene.2016.12.011

[15] X.G. Huang, Y.H. Yang, X. Cheng et al., Effect of spray on performance of the hydrogen mitigation system during LB-LOCA for CPR1000 NPP. Ann. Nucl. Energy. 38, 1743-1750 (2011). doi: 10.1016/j.anucene.2011.04.003

[16] B.G. Jeon, H.C. NO, Thermal-hydraulic evaluation of passive containment cooling system of improved APR+ during LOCAs. Nucl. Eng. Des. 278, 190-198 (2014). doi: 10.1016/j.nucengdes.2014.07.038 
[17] S. Şahin, MS. Sarwar, Hydrogen hazard and mitigation analysis in PWR containment. Ann. Nucl. Energy. 58, 132-140 (2013). doi: 10.1016/j.anucene.2013.03.001

[18] S.R. Ravva, K.N. Iyer, A.J. Gaikwad, Development of sump model for containment hydrogen distribution calculations using CFD code. Nucl. Eng. Des. 295, 429-440 (2015). doi: 10.1016/j.nucengdes.2015.10.00

[19] J.M. Martín-Valdepeñas, M.A. Jiménez, F. Martín-Fuertes et al., Improvements in a CFD code for analysis of hydrogen behaviour within containments. Nucl. Eng. Des. 237, 627-647 (2007). doi: 10.1016/j.nucengdes.2006.09.002

[20] A.M. Gómez-Torres, E. Sáinz-Mejía, J.V. Xolocostli-Munguía et al., CFD analysis of hydrogen volumetric concentrations in a Hard Venting Containment System of a Mark II BWR. Ann. Nucl. Energy. 85, 552-565 (2015). doi: 10.1016/j.anucene.2015.06.008

[21] G.P. Choi, D.Y. Kim, K.H. Yoo et al., Prediction of hydrogen concentration in nuclear power plant containment under severe accidents using cascaded fuzzy neural networks. Nucl. Eng. Des. 300, 393-402 (2016). doi: 10.1016/j.nucengdes.2016.02.015

[22] T. Szabó, F. Kretzschmar, T. Schulenberg., Obtaining a more realistic hydrogen distribution in the containment by coupling MELCOR with GASFLOW. Nucl. Eng. Des. 269, 330-339 (2014). doi: 10.1016/J.NUCENGDES.2013.07.009

[23] W. Breitung, P. Royl, Procedure and tools for deterministic analysis and control of hydrogen behavior in severe accidents. Nucl. Eng. Des. 202, 249-268 (2000). doi: $10.1016 / \mathrm{S} 0029-5493(00) 00380-0$

[24] E. Bachellerie, F. Arnould, M. Auglaire et al., Generic approach for designing and implementing a passive autocatalytic recombiner PAR-system in nuclear power plant containments. Nucl. Eng. Des. 221, 151-165 (2003). doi: 10.1016/S0029- 
5493(02)00330-8

[25] AEOI (Atomic Energy Organization of Iran), BNPP Final Safety analysis Report (FSAR). Iran, 2007.

[26] I.L. Drell, F.E. Belles, Survey of Hydrogen Combustion Properties. United States: NASA Technical report, 1958.

[27] H. Karwat, J. Bardelay, T. Hashimoto, SOAR on Containment Thermalhydraulics and Hydrogen Distribution. OECD/NEA/CSNI, 1999.

[28] K.K. Murata, D.C. William, J. Tills et al., Code manual for CONTAIN 2.0; A computer code for Nuclear Reactor Containment Analysis. Albuquerqu, NM: Sandia National Lab, 1997.

[29] R.O. Gauntt, R.K. Cole,C.M. Erickson et al., MELCOR Computer Code Manuals. NUREG/CR-6119, Rev. 2, 2000. 


\section{Figure Captions:}

Figure 1. BNPP containment structure

Figure 2. Hydrogen generation profile

Figure 3. Cells layout diagram and connections

Figure 4. Spray cycle in BNPP

Figure 5. Passive autocatalytic hydrogen recombiner

Figure 6. Profile of mass release from break [25]

Figure 7. Profile of energy release from break [25]

Figure 8. Short term average pressure profile

Figure 9. Long term average pressure profile

Figure 10. Short term temperature profile of cell 3 (SG compartment 2, bubbler, room of filters) Figure 11. Short term temperature profile of cell 18 (Staircases and adjoining rooms, chamber of the backup converter. Pumps of RCP oil cooling system, pipelines.)

Figure 12. Short term temperature profile of cell 22 (Reactor hall space between the cylindrical wall)

Figure 13. Short term temperature profile of cell 23 (Reactor hall space above the cylindrical wall)

Figure 14. Hydrogen distribution profile in cell 3

Figure 15. Hydrogen distribution profile in cell 18

Figure 16. Hydrogen distribution profile in cell 22

Figure 17. Hydrogen distribution profile in cell 23

Figure 18. Hydrogen and thermal-hydraulic distribution map in last second of the accident (about $10^{5}$ seconds) 